\title{
1D modelling of internal oxidation phenomena with X-FEM
}

\author{
Éric Feulvarch ${ }^{1}$, Jean-Christophe Roux ${ }^{2}$ and Jean-Michel Bergheau ${ }^{1}$ \\ 1 Univ. Lyon, LTDS, UMR 5513 CNRS/ECL/ENISE, 58 rue Jean Parot, 42023 Saint-Étienne Cedex 2, France \\ 2 DIPI, EA 3719 ENISE, 58 rue Jean Parot, 42023 Saint-Étienne Cedex 2, France
}

Received 13 July 2010, Accepted 13 July 2010

\begin{abstract}
The simulation of simultaneous diffusion and precipitation of a chemical element during internal oxidation phenomena is presented here, from X-FEM method. This technique seems to be really appropriate when solubility products are very low, or even almost null. In this case, a precipitation front appears and should be properly represented by the numerical simulation. The X-FEM method is then of strong interest, since it allows to know precisely the position of the front all the time of simulation, without remeshing.
\end{abstract}

Key words: Diffusion / precipitation / internal oxidation / discontinuity / X-FEM

\section{Introduction}

The problem considered here is refering to oxygen atoms diffusion through a metallic matrix wich contains aluminum atoms in a very weak quantity ("diluted solutions hypothesis"). Aluminum oxide $\mathrm{Al}_{2} \mathrm{O}_{3}$ formation may be then produced in the metallic matrix in the form of an internal oxidation. Recently, Flauder et al. [1] proposed a numerical approach by coupling a diffusion model for each chemical species with the mass action law. This method is based on explicit 1D finite differences in space coupled with explicit time integration. However, explicit time integration requires very small time steps, and this notably increases computational time.

Latterly, Feulvarch et al. [2] extend this approach to finite elements in space, coupled to an implicit time integration using Euler's algorithm. Advantages of such a method are obvious:

- finite elements using instead of finite differences, which makes very easier $2 \mathrm{D}$ and $3 \mathrm{D}$ meshing;

- implicit time integration, which allows to use larger time steps, with no visible deterioration of results quality.

The aim of this paper is to propose an eXtended-Finite Element Method type solution in the case of a precipitation induced by a very low solubility product. Indeed, in such a situation, total mass fraction profile presents a discontinuity at the precipitation front in a similar way to enthalpy in presence of an isothermal transformation [3]. $\mathrm{X}-\mathrm{FEM}$ technique is particulary well suited and presents an obvious interest for representing this front.
An X-FEM type discretization based on the works of Chessa et al. [4] for an isothermal state change is suggested here, by integrating the level-set technique.

\section{Governing equations}

The problem context and its equations are briefly exposed here; for more details, report to [1].

Let $C_{\mathrm{O}}$ and $C_{\mathrm{Al}}$ be the two concentrations corresponding to oxygen and aluminum atoms respectively.

Let $F_{\mathrm{O}}$ and $F_{\mathrm{Al}}$ denote the total mass fractions of oxygen and aluminum respectively, that is including the atoms embedded in alumina $\left(\mathrm{Al}_{2} \mathrm{O}_{3}\right)$ precipitate, plus those in solution in the matrix.

Finally, let $P_{\mathrm{Al}_{2} \mathrm{O}_{3}}$ denotes the mass fraction of $\mathrm{Al}_{2} \mathrm{O}_{3}$ precipitate.

In some elementary volume and counting the number of atoms of oxygen and aluminum in all their forms (embedded in precipitates and in solution in the matrix), one gets the following balance equations:

$$
\begin{aligned}
\frac{F_{\mathrm{O}}}{M_{\mathrm{O}}} & =\frac{C_{\mathrm{O}}}{M_{\mathrm{O}}}+3 \frac{P_{\mathrm{Al}_{2} \mathrm{O}_{3}}}{M_{\mathrm{Al}_{2} \mathrm{O}_{3}}} \\
\frac{F_{\mathrm{Al}}}{M_{\mathrm{Al}}} & =\frac{C_{\mathrm{Al}}}{M_{\mathrm{Al}}}+2 \frac{P_{\mathrm{Al}_{2} \mathrm{O}_{3}}}{M_{\mathrm{Al}_{2} \mathrm{O}_{3}}}
\end{aligned}
$$

where $M_{\mathrm{O}}$ and $M_{\mathrm{Al}}$ denote the atomic masses of oxygen and aluminum respectively, and $M_{\mathrm{Al}_{2} \mathrm{O}_{3}}$ denotes the molecular mass of $\mathrm{Al}_{2} \mathrm{O}_{3}$. 


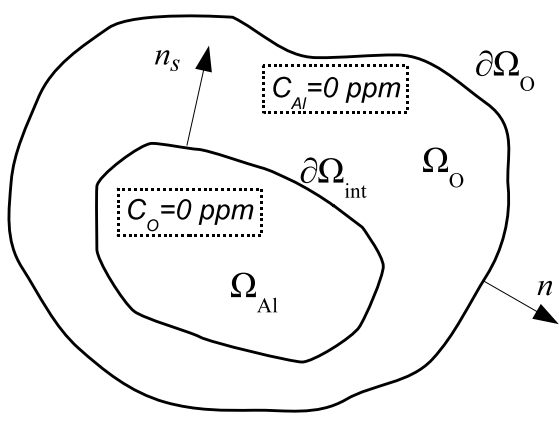

Fig. 1. Topology of the domain $\Omega$.

Fluxes of oxygen and aluminum elements are given by the following expressions:

$$
\begin{aligned}
J_{\mathrm{O}} & =-D_{\mathrm{O}} \operatorname{grad} C_{\mathrm{O}} \\
\text { and } \quad J_{\mathrm{Al}} & =-D_{\mathrm{Al}} \operatorname{grad} C_{\mathrm{Al}}
\end{aligned}
$$

where $D_{\mathrm{O}}$ et $D_{\mathrm{Al}}$ denote the diffusion coefficients of oxygen and aluminum respectively. In these expressions, concentrations are assumed to be equal to thermodynamic activities.

The relation between the total mass fractions of oxygen and aluminum and their concentrations in the matrix are assumed to be governed by local and instantaneous thermodynamic equilibrium, that is by the law of mass action:

$$
\left\{\begin{array}{l}
P_{\mathrm{Al}_{2} \mathrm{O}_{3}}=0 \quad \text { and } \quad C_{\mathrm{Al}}^{2} C_{\mathrm{O}}^{3} \leq K_{\mathrm{Al}_{2} \mathrm{O}_{3}} \\
\text { or } \\
P_{\mathrm{Al}_{2} \mathrm{O}_{3}}>0 \quad \text { and } \quad C_{\mathrm{Al}}^{2} C_{\mathrm{O}}^{3}=K_{\mathrm{Al}_{2} \mathrm{O}_{3}}
\end{array}\right.
$$

where $K_{\mathrm{Al}_{2} \mathrm{O}_{3}}$ denotes alumina solubility product.

In practice, solubility product can be very low and can reach the order value $10^{-18}(\mathrm{ppm})^{5}$ for alumina [1]. This implies to split the domain $\Omega$ of study into two subdomains $\Omega_{\mathrm{O}}$ and $\Omega_{\mathrm{Al}}$, as suggested by Wagner $[5,6]$. These two subdomains are separated by a precipitation front $\partial \Omega_{\text {int }}$ which spreads with speed $v$ (see Fig. 1).

Indeed, when $K_{\mathrm{Al}_{2} \mathrm{O}_{3}}$ is null in Equation (3), oxygen and aluminum cannot coexist in dissolved form. Thus one gets either $C_{\mathrm{O}}=0 \mathrm{ppm}$ or $C_{\mathrm{Al}}=0 \mathrm{ppm}$ on both sides of frontier $\partial \Omega_{\text {int }}$

\section{Modelling and discretization}

The studied problem can be formulated as follows: find $C_{\mathrm{O}}$ and $C_{\mathrm{Al}}$ defined in the domain $\Omega \times[0 ; T]=\Omega_{\mathrm{O}} \cup$ $\Omega_{\mathrm{Al}} \times[0 ; T]$ such as:

$$
\left\{\begin{array}{l}
\frac{\partial C_{\mathrm{O}}}{\partial t}=\operatorname{div}\left(D_{\mathrm{O}} \operatorname{grad} C_{\mathrm{O}}\right) \quad \text { in } \Omega_{\mathrm{O}} \\
D_{\mathrm{O}} \operatorname{grad} C_{\mathrm{O}} \cdot n=J_{\mathrm{O}}^{(\mathrm{set})}+\lambda_{\mathrm{O}}\left(C_{\mathrm{O}}^{(\mathrm{set})}-C_{\mathrm{O}}\right) \text { on } \partial \Omega_{\mathrm{O}}
\end{array}\right.
$$

and

$$
\frac{\partial C_{\mathrm{Al}}}{\partial t}=\operatorname{div}\left(D_{\mathrm{Al}} \operatorname{grad} C_{\mathrm{Al}}\right) \quad \text { in } \Omega_{\mathrm{Al}}
$$

with initial conditions $C_{\mathrm{O}}(t=0)=0$ and $C_{\mathrm{Al}}(t=0) \neq 0$, where $J_{\mathrm{O}}^{(\mathrm{set})}$ is a setted incoming flux, $C_{\mathrm{O}}^{(\mathrm{set})}$ a setted value and $\lambda_{\mathrm{O}}$ the oxygen transfert coefficient.

The conditions at the precipitation front $\partial \Omega_{\text {int }}$ read:

$$
C_{\mathrm{Al}}=C_{\mathrm{O}}=0
$$

and

$$
-2 D_{\mathrm{O}} \operatorname{grad} C_{\mathrm{O}}=3 D_{\mathrm{Al}} \operatorname{grad} C_{\mathrm{Al}}
$$

Variational formulations are obtained by multiplying Equations (4) and (5) by test functions $C_{\mathrm{O}}^{*}$ et $C_{\mathrm{Al}}^{*}$, and by integrating over the whole domain $\Omega$ :

$$
\begin{array}{r}
\forall C_{\mathrm{O}}^{*}, \quad \int_{\Omega} \frac{\partial C_{\mathrm{O}}}{\partial t} C_{\mathrm{O}}^{*} \mathrm{~d} V+\int_{\Omega} D_{\mathrm{O}} \operatorname{grad} C_{\mathrm{O}} \cdot \operatorname{grad} C_{\mathrm{O}}^{*} \mathrm{~d} V \\
\quad+\int_{\partial \Omega_{\mathrm{O}}} \lambda_{\mathrm{O}} C_{\mathrm{O}} C_{\mathrm{O}}^{*} \mathrm{~d} S \\
-\int_{\partial \Omega_{\mathrm{O}}}\left(J_{\mathrm{O}}^{(\mathrm{set})}+\lambda_{\mathrm{O}} C_{\mathrm{O}}^{(\mathrm{set})}\right) C_{\mathrm{O}}^{*} \mathrm{~d} S=0
\end{array}
$$

and

$$
\begin{aligned}
\forall C_{\mathrm{Al}}^{*}, \quad \int_{\Omega} \frac{\partial C_{\mathrm{Al}}}{\partial t} C_{\mathrm{Al}}^{*} \mathrm{~d} V \\
\quad+\int_{\Omega} D_{\mathrm{Al}} \operatorname{grad} C_{\mathrm{Al}} \cdot \operatorname{grad} C_{\mathrm{Al}}^{*} \mathrm{~d} V=0
\end{aligned}
$$

Equations (7) and (8) can be integrated over the whole domain $\Omega$, since the concentrations $C_{\mathrm{O}}$ and $C_{\mathrm{Al}}$ equal zero on $\Omega_{\mathrm{Al}}$ and $\Omega_{\mathrm{O}}$ respectively.

The level-set field is computed in $1 \mathrm{D}$ by means of a process based on dichotomy. This iterative process computes zero value of the integral form of the local conservative law expressed in Equation (2):

$$
\begin{aligned}
\forall t, \quad \int_{\Omega} C_{\mathrm{Al}}^{(0)} \mathrm{d} v-\int_{\Omega_{\mathrm{O}}} 2 \frac{M_{\mathrm{Al}}}{M_{\mathrm{Al}_{2} \mathrm{O}_{3}}} & P_{\mathrm{Al}_{2} \mathrm{O}_{3}}^{(\mathrm{t})} \mathrm{d} v \\
& -\int_{\Omega_{\mathrm{Al}}} C_{\mathrm{Al}}^{(\mathrm{t})} \mathrm{d} v=0
\end{aligned}
$$

where $C_{\mathrm{Al}}^{(0)}$ and $C_{\mathrm{Al}}^{(\mathrm{t})}$ denote initial value of $C_{\mathrm{Al}}$ and its value at time $t$. Following the Wagner's theory, $P_{\mathrm{Al}_{2} \mathrm{O}_{3}}^{(\mathrm{t})}$ can be considered as constant in $1 \mathrm{D}$, and can be computed from its analytical form. One can note that Equation (9) is the integral form of Equation (6) expressed on $\partial \Omega_{\text {int }}$.

To solve Equations (7) and (8), concentration fields are approximated by X-FEM method in the following way:

$$
C(x, t)=\sum_{i \in I_{\mathrm{r}}} N_{i}(x) \lambda_{i}(t)+\sum_{j \in I_{\mathrm{e}}} N_{j}^{\prime}(x) \lambda_{j}^{\prime}(t)
$$

where:

- $I_{\mathrm{r}}$ denotes the set of regular nodes' indices, $I_{\mathrm{e}}$ is the set of enriched nodes' indices (see Fig. 2), and $I_{\mathrm{r}} \cup I_{\mathrm{e}}=I$ : set of all nodes' indices; 


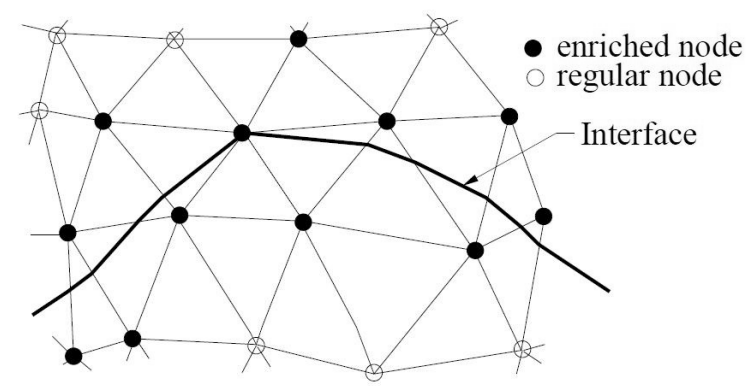

Fig. 2. Nodes which are enriched, from Chessa et al. [4].

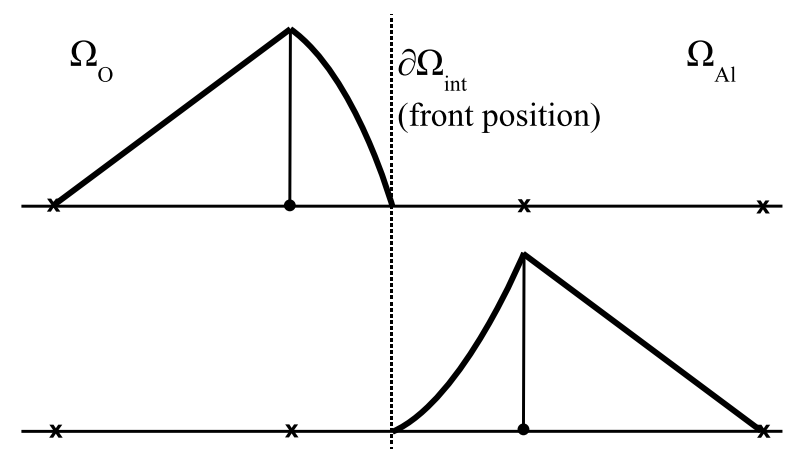

Fig. 3. Modified shape functions for both sides of the precipitation front.

- $\lambda_{i}(t)$ and $\lambda_{j}^{\prime}(t)$ are nodal values;

- $N_{i}(x)$ are classical shape functions;

- $N_{j}^{\prime}(x)$ are modified shape functions defined as:

$$
N_{j}^{\prime}(x)=\left\{\begin{array}{ll}
N_{j}\left|\varphi_{j}\right| & \text { if } \varphi>\varphi_{j} \\
\sqrt{N_{j}+\varepsilon}\left(\frac{|\varphi-| \varphi||}{2}\right) \\
\text { for oxygen, } \\
\sqrt{N_{j}+\varepsilon}\left(\frac{|\varphi+| \varphi||}{2}\right) \\
\text { for aluminum, }
\end{array}\right\} \text { otherwise }
$$

where $\varphi_{j}(t)$ are nodal values of the level-set field $\varphi(x, t)$, which is defined by:

$$
\varphi(x, t)=\sum_{k \in I_{\mathrm{r}}} N_{k}(x) \varphi_{k}(t)
$$

and $\varepsilon$ is a small paramater needed to compute the gradient.

This definition of the modified shape functions does not include the analytical solution of the Wagner's problem in 1D, because its expression is too complex to be computed. So, a square root is used to define the $N_{j}^{\prime}(x)$ functions in order to get a quasi-linear approximation (see Fig. 3).
Finally, the solving process is stated at each time step $t+\Delta t$ as:

Knowing $C_{\mathrm{O}}^{(t+\Delta t), k}, C_{\mathrm{Al}}^{(t+\Delta t), k}$ and $\varphi^{(t+\Delta t), k}$ computed at iteration $k$,

1. compute new front position $\varphi^{(t+\Delta t), k+1}$ from Equation (9) using dichotomy;

2. compute $C_{\mathrm{O}}^{(t+\Delta t), k+1}$ and $C_{\mathrm{Al}}^{(t+\Delta t), k+1}$ from $\varphi^{(t+\Delta t), k+1}$ and Equations (7) and (8) using an implicit EuLer algorithm; $\left(C_{\mathrm{O}}^{(t+\Delta t), k+1}\right.$ and $C_{\mathrm{Al}}^{(t+\Delta t), k+1}$ are respectively forced to zero in $\Omega_{\mathrm{Al}}$ and $\Omega_{\mathrm{O}}$ );

3. convergence test: if Equation (9) is satisfied, then STOP else $k=k+1$

\section{Example}

We consider diffusion and precipitation in a thick, laterally infinite plate. The problem is then $1 \mathrm{D}$ in the direction $x$ perpendicular to the surface of this plate.

The values of the diffusion coefficients of oxygen and aluminum are $D_{\mathrm{O}}=8.02 \mu \mathrm{m}^{2} \cdot \mathrm{s}^{-1}$ and $D_{\mathrm{Al}}=5.58 \times$ $10^{-4} \mu \mathrm{m}^{2} . \mathrm{s}^{-1}$.

The plate is initially free of oxygen and the initial total fraction of aluminum (determined by the grade of the steel) is $1200 \mathrm{ppm}$.

On the left bounding surface, at $x=0$, a fixed oxygen concentration of $9.24 \times 10^{-3} \mathrm{ppm}$ is imposed and the flux of aluminum is zero.

On the right bounding surface, the fluxes of both oxygen and aluminum are zero.

Oxygen gradually penetrates into the plate (inward diffusion) at $x=0$, thus inducing precipitation of $\mathrm{Al}_{2} \mathrm{O}_{3}$ near the left surface. This precipitation generates an aluminum "sink" which causes aluminum to diffuse toward the left surface (outwards diffusion).

For this problem, the analytical position $\xi(t)$ of the precipitation front is given by:

$$
\xi(t)=2 \eta \sqrt{D_{\mathrm{O}} t}
$$

where $\eta$ is an ancillary dimensionless unknown.

Condition (6) in Section 3 at the precipitation front yields the following equation on $\eta$, which implicitly provides its value:

$$
\frac{\exp \left(\eta^{2}\right) \operatorname{erf} \eta}{\sqrt{\frac{D_{\mathrm{O}}}{D_{\mathrm{A} 1}}} \exp \left(\eta^{2} \frac{D_{\mathrm{O}}}{D_{\mathrm{Al}}}\right) \operatorname{erfc}\left(\eta \sqrt{\frac{D_{\mathrm{O}}}{D_{\mathrm{Al}}}}\right)}=\frac{C_{\mathrm{O}}(0, t)}{\frac{3}{2} C_{\mathrm{Al}}(x, 0)}
$$

Solving the diffusion Equations (4) and (5) with the initial and boundary conditions mentionned in Section 3, one gets the following expressions of the concentrations:

$$
\left\{\begin{array}{l}
\frac{C_{\mathrm{O}}(x, t)}{C_{\mathrm{O}}(0, t)}=1-\frac{\operatorname{erf}\left(x /\left(2 \sqrt{D_{\mathrm{O}}} t\right)\right.}{\operatorname{erf} \eta} \quad \text { for } 0 \leq x \leq \xi(t) \\
\frac{C_{\mathrm{Al}}(x, t)}{C_{\mathrm{Al}}(x, 0)}=1-\frac{\operatorname{erfc}\left(x /\left(2 \sqrt{D_{\mathrm{Al}}}\right)\right)}{\operatorname{erfc}\left(\eta \sqrt{\frac{D_{\mathrm{O}}}{D_{\mathrm{Al}}}}\right)} \quad \text { for } x \geq \xi(t)
\end{array}\right.
$$




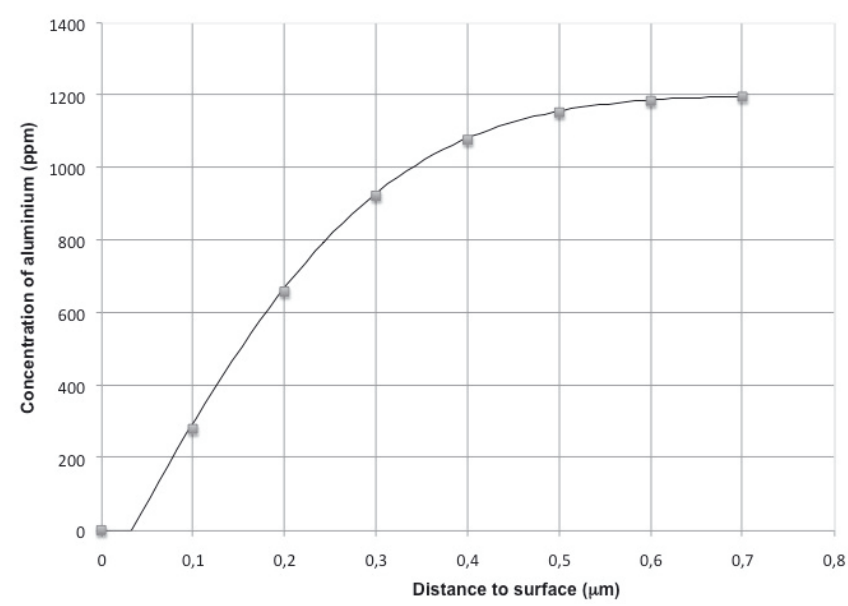

Fig. 4. Distribution of concentration of aluminum in a thick plate at $t=50 \mathrm{~s}$. $\mathbf{a r e}$ computed values at knots compared with Wagner's solution (-).

For the simulation, the mesh is composed of two-node elements. The element size is equal to $0.1 \mu \mathrm{m}$. The time step $\Delta t$ is uniform. Figure 4 displays the concentration of aluminum at time $t=50 \mathrm{~s}$, as a function of the distance $x$ from the left surface. Two types of results are shown:

1. those obtained at nodes with the eXtended Finite Element Method developed in this paper, with a timestep of $5 \mathrm{~s}$;

2. those corresponding to the classical analytical solution of $[6]$.

One can see that the agreement with Wagner's solution is excellent, is spite of the numerical difficulty of this example which involves a discontinuous total fraction of aluminum.

Figure 5 displays the evolution of the precipitation front in time.

\section{Conclusion}

As it can be seen in example part, the X-FEM method is well adapted to this kind of problem, and the computed results match with the analytical solution in a very satisfaying manner. Indeed, the new algorithm allows to address even numerically difficult cases involving very small

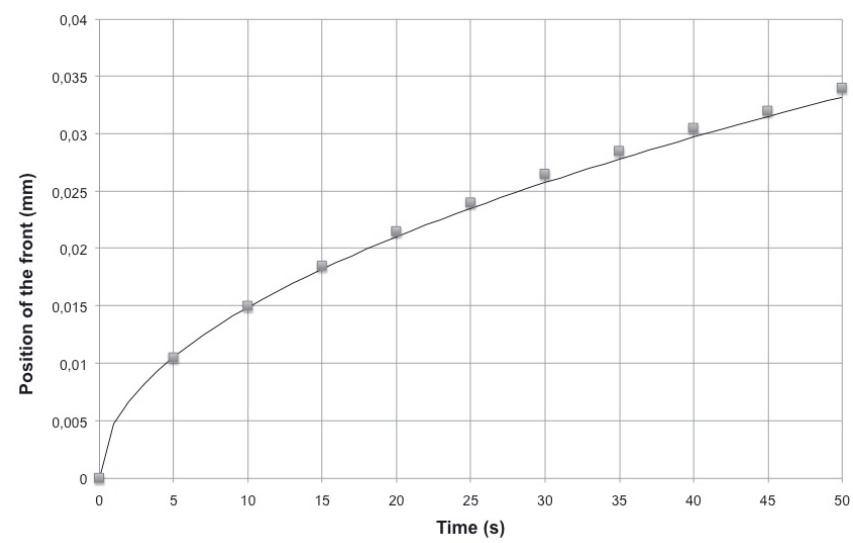

Fig. 5. Evolution of the precipitation front in time. $\square$ are computed values compared with Wagner's solution (-).

solubility product of the precipitate phases and dicontinous fluxes of elements.

Actual work is aim to extend this approach in $2 \mathrm{D}$ and $3 \mathrm{D}$, and in the case of several chemical elements which can produce many precipitates, with almost null solubility products.

\section{References}

[1] P. Flauder, D. Huin, J.-B. Leblond, Numerical simulation of internal oxidation of steels during annealing treatments, Oxid. Met. 64 (2005) 131-167

[2] E. Feulvarch, J.-M. Bergheau, J.-B. Leblond, An implicit finite element algorithm for the simulation of diffusion with phase changes in solid, Int. J. Num. Methods Eng. 78 (2009) 1492-1512

[3] E. Feulvarch, J.-M. Bergheau, An implicit fixed-grid method for the finite element analysis of heat transfer involving phase changes, Numer. Heat Transf. Part B 51 (2007) 585-610

[4] J. Chessa, P. Smolinski, T. Belytschko, The extended finite element method for solidification problems, Int. J. Num. Methods Eng. 53 (2002) 1959-1977

[5] C. Wagner, Theorical analysis of the diffusion processes determining the oxidation rate of alloys, J. Electrochem. Soc. 99 (1952) 369-380

[6] C. Wagner, Reaktionstypen bei der oxydation von Legierugen, Z. Elektrochem. 63 (1959) 772-782 